\title{
Perceived Function: An Investigation into a Product Advantage between Aesthetics and Function
}

\author{
Satoru Goto ${ }^{*}$, Yuuki Shigemoto², Shuichi Ishida ${ }^{3}$
}

\begin{abstract}
This study involved an empirical comparison of product competitiveness driven by aesthetic and technological innovations in a mature market. This study began with a theoretical idea that users may perceive and evaluate technology development through the visible form of a product. Statistical analyses of user reviews of digital cameras showed that the impact of technology development on competitiveness was greater than that of aesthetic changes. The results demonstrated that users did not leverage product appearance for the recognition of technology development. Moreover, the findings show that specification information had a greater influence on product advantage when users did not visually perceive technological improvement. These results may indicate that manufacturers have not yet fully exploited product design for maximising product advantage in the mature market.
\end{abstract}

Keywords: Function; Aesthetics; Perceived function; Utilitarian and hedonic value.

Submitted: March $4^{\text {th }}, 2019$ / Approved: July $11^{\text {th }}, 2019$

\section{Introduction}

In recent years, design has been re-appreciated as a driver of successful new product development (NPD). Many studies have shown that advanced design, or the involvement of advanced industrial designers in $R \& D$ processes, results in the improvement of product performance (Gemser and Leenders, 2001; Hertenstein, Platt, and Veryzer, 2005; Rubera and Droge, 2013; Walsh, Roy, Bruce, and Potter, 1992). The studies focused on 'design' have particularly emphasised the emotional value represented by aesthetic satisfaction that product forms evoke in consumers' minds (Creusen, 2011). In contrast, the major focus of studies in the area of innovation management has been on functional value, that is, the practical benefits that product performance offers consumers (Candi, 2006; Candi and Saemundsson, 2011).

However, consumers also perceive functional value in the form of a product (Bloch, 1995; Hoegg and Alba, 2011). For example, the transparent body of the Dyson DC01 vacuum cleaner literally shows the functional advantage of the bagless system (Talke, Salomo, Wieringa, and Lutz, 2009). In this sense, consumers actually see the main functional feature as a perceptual icon of the product (see Kreuzbauer and Malter, 2005). This example indicates that functional features presented by product design can be valued by consumers as both emotional and functional (Buganza, Dell'Era, Pellizzoni, Trabucchi and Verganti, 2015; Crilly, Moultrie, and Clarkson, 2004; Hoegg and Alba, 2011). The present paper defines functional features that can be a source of both values as perceived function (see Figure 1).
Figure 1. Perceived Function

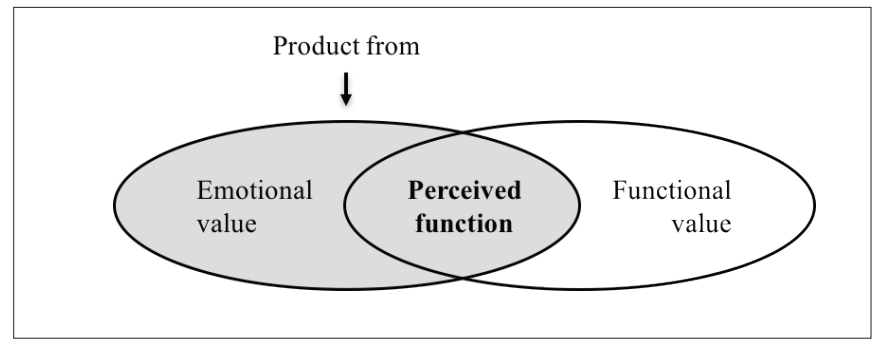

Eisenman (2013) emphasised that the role of product form varies depending on the extent to which a consumer understands the functional value of an item. Once consumers understand what a new product in the same category does, they evaluate the evolution of the functions of the new item compared to those of previous models (Crilly, Moultrie and Clarkson, 2004; Kaplan and Tripsas, 2008; Mugge and Dahl, 2013). However, unclear incremental technological developments in product form would make it difficult for users to recognise the upgrades from previous models. Therefore, once new technology has become common in the market, consumers begin to respond to its aesthetic aspects, which continue to be new to them, rather than the functional aspects (Crilly, Moultrie and Clarkson, 2004; Eisenman, 2013). Whilst aesthetic innovation is important at this stage, if a new product form differs distinctly from a dominant design in the market, consumers may have negative impressions because of the high learning cost of familiarising themselves with the new item (Bornemann, Homborg, and Schöler, 2015; Thompson, Hamilton, and Rust, 2005). Therefore, the magnitude of consumers' positive (or negative) responses towards changes in product form may allow us to gain a better understanding of product advantages achieved through design.

1) College of Business Administration, Ritsumeikan University, Ibaraki, Osaka, Japan.

2) Faculty of Contemporary Society, Toyama University of International Studies, Toyama, Japan.

3) Graduate School of Technology Management, Ritsumeikan University, Ibaraki, Osaka, Japan.

*Corresponding author: goto-s@fc.ritsumei.ac.jp 
Nevertheless, most literature on consumer response to products does not address function and perceived function, posing a challenge to researchers seeking the product advantage communicated by the product form. Consequently, the knowledge gap between function and perceived function and aesthetics has rarely been addressed, whilst the synergetic interaction between the form and function of a product has attracted considerable attention (Ravasi and Stigliani, 2012). Furthermore, from a practical perspective, despite investments by companies that have developed new functions, a product with too many functions that increases learning costs does not seem ideal for consumers (Borneman et al., 2015; Hoegg and Alba, 2011; Thompson et al., 2005). As a result, most functions of a product are often not utilised, or even realised, by consumers unless they take the time to examine the product's specifications (descriptions). For these academic and practical reasons, this paper suggests that issues regarding product form should be addressed and explored through a comprehensive view of their impacts on both aesthetic and functional advantages (product performance).

To address this research question, this empirical study examines the extent to which the evolution of function is perceived by consumers through product form and then captures consumer perceptions of product advantages based on product form (aesthetics and perceived function) and function. This study employs a data set to represent users' evaluations of the product that were made based on all their sensory perceptions of compact digital cameras. The initial exploratory analysis is conducted to identify perceived function and aesthetic impressions in the data. Next, confirmatory factor analysis is employed to examine the extent to which there is a relationship between function and perceived function, which are identified by exploratory factor analysis; then, the extent to which consumers assess the impact of the function, perceived function, and aesthetic impression on product advantage.

\section{Literature review and conceptual framework}

Products offer consumers functional solutions and emotional satisfaction. Innovation studies tend to expand their discussions to a dichotomous view between functionality and product form. However, users do demonstrate sensory reactions to technology and function, which partially comprise the users' overall emotional response to a product form. The arguments regarding users' emotional responses to the functional and meaningful features of a product may be better grasped by considering the value that people find in products.

\section{Product values}

Improved descriptions of perspectives regarding product values have been sought (Boztepe, 2007; Elliott, 1997; Kenrick et al., 2009; Lichtenstein and Burton, 1989; Oude Ophuis and Van Trijp, 1995; Sheth, Newman, and Gross, 1991; Sweeney and Soutar, 2001; Turel, Serenko, and Bontis, 2010). This study found that the arguments regarding product value can be summarised by two simple aspects: a value that is provided by the physical function of a product and makes changes in the real world is known as utilitarian value; and that which provides emotional satisfaction and makes changes within one's mind is known as hedonic value (Chitturi, Raghunathan, and Mahajan, 2008; Hanzaee and Baghi, 2011; Hirschman and Holbrook, 1982).
In the context of business, the cost that one is willing to pay is determined by the consumer's judgement of the perceived price and quality (Chang and Wildt, 1994; Shetty, 1987; Steenkamp, 1990; Toivonen, 2012). Consequently, the perception of a product's features (utilitarian and hedonic) that identify the product quality for a user is a crucial influence on consumer attitudes towards items. A framework that captures product value in utilitarianism and hedonism may therefore be useful for an in-depth consideration of what consumers find beneficial in different situations. However, the value of products may not be fully understood if the goods are regarded as encompassing either utilitarian or hedonic value. For example, certain consumers may purchase automobiles for the purpose of transportation, whilst others may regard the same products as a representation of their artistic sense or as a symbol of their status. Thus, it would be more appropriate to posit that every product innately has both utilitarian and hedonic features that together comprise the perceived value of products and that what matters is the ratio between the two (Steenkamp, 1990; Voss, Spangenberg and Grohmann, 2003). This paper uses the terms utilitarian value and hedonic value to refer to these product features (Figure 2).

Figure 2. Structure of Utilitarian and Hedonic Values

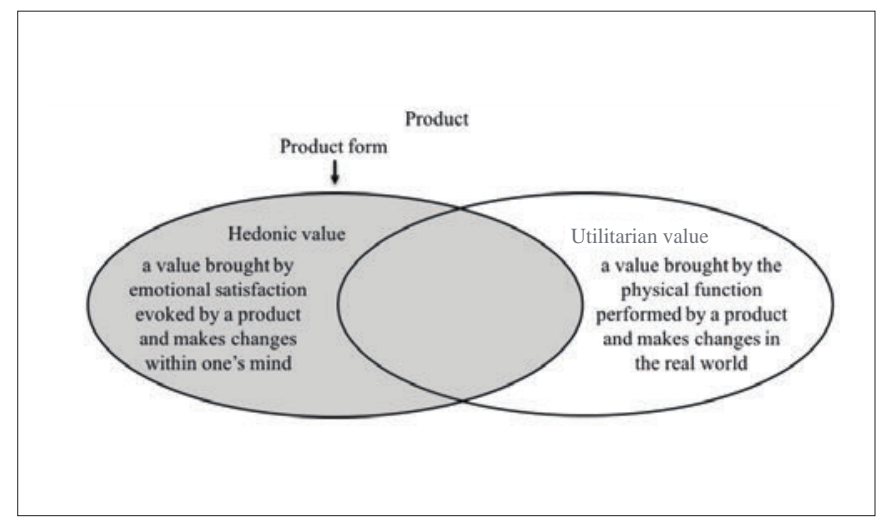

\section{Sensory responses to product form}

Researchers have striven to empirically explore the interaction between products and consumers through their senses. Bloch (1995) developed a psychological model of the consumer response to products and indicated the importance of seeking an 'ideal' form that must satisfy design constraints and achieve superiority to competitors both in utilitarian and hedonic values. Crilly et al. (2004) particularly focused on the consumer's visual response to product form. They revised the literature across a wide range of disciplines and concluded that product form visually communicates an aesthetic impression, semantic interpretation, and symbolic association, referring to the beauty of a product's appearance, the functional features (including perceived function and ergonomics, recognised through product form), and the images and meanings associated with a product. These are major indexes of perception that users obtain through observing the product. In fact, other researchers have discussed these three domains in (innovative) products using different terms. Table 1 provides a summary of the studies and the expressions used in them. 
Table 1. Three-dimensional Segmentation of Sensory Responses to Product Form

\begin{tabular}{|c|c|c|c|}
\hline & Aesthetic Aspect & Functional Aspect & Symbolic Aspect \\
\hline Crilly, Moultrie, and Clarkson (2004) & Aesthetic interpretation & Semantic interpretation & Symbolic association \\
\hline Norman (2004) & Visceral level & Behavioural level & Reflective level \\
\hline Candi (2006) & Visceral design & Functional design & Experiential design \\
\hline Rampino (2011) & Aesthetic & Use & Meaning \\
\hline Eisenman (2013) & Aesthetic information & $\begin{array}{l}\text { Functional } \\
\text { information }\end{array}$ & Symbolic information \\
\hline
\end{tabular}

These studies regard product form as an important communicator of aesthetic, functional, and symbolic aspects in users' intuitive understandings (Crilly, Good, Matravers, and Clarkson, 2008; Crilly, Maier, and Clarkson, 2008). Consequently, these studies indicate that technology and product form are not isolated from each other, and we might assume that users recognise the fruition of $\mathrm{R} \& \mathrm{D}$ through product form. Product aesthetic and function-which are main sources of hedonic and utilitarian values, respectively-emerge and shape the product. The product features overlapping both domains are perceived function and ergonomics, as shown in Figure 3.

Figure 3. Value and Sensory Response to Product Form

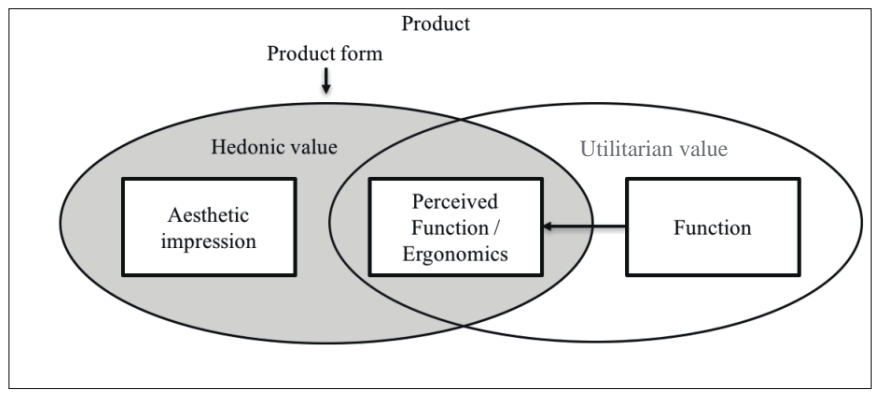

\section{Conceptual framework}

Recent studies have used empirical tests to explore the relationship between product form and functional value. Moon, Park, and Kim (2015) and Borneman et al. (2015) conceptualised product form into ergonomic, aesthetic, and functional values to identify the main drivers of product advantage. The former study found that product innovativeness was highly appreciated when all the aforementioned values were found to be high. However, the latter study claims that consumers evaluate ergonomic and functional value independently based on product advantage. The reason that these findings are inconsistent is that the former examined the consumer perception of functions without providing linguistic descriptions of the functions to survey respondents. Meanwhile, the latter provided text information of the functions when examining the perception responses of consumers to products. In other words, Moon et al., (2015) explored perceived function, whilst Borneman et al. (2015) examined consumer response to function (Figure.4). As such, the absence of the concept of perceived function caused confusion and resulted in contradicting reports.
Figure 4. Framework of Extant Literature

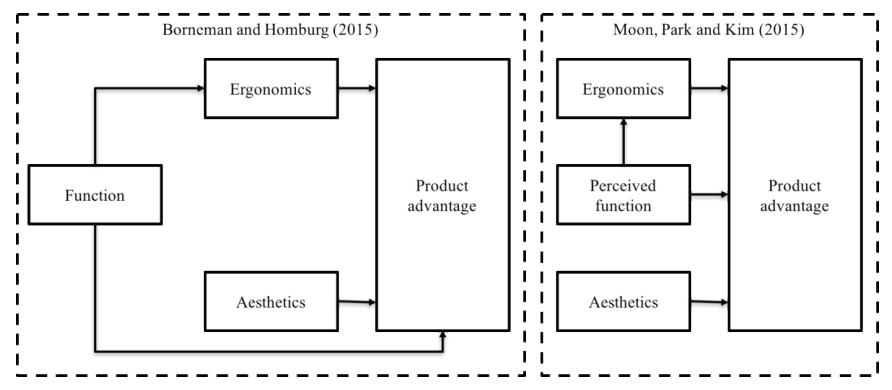

Meanwhile, Hoegg and Alba (2011), who explored the relationship between function and perceived function, found that consumers even appreciated perceived function when they were provided with less information about function. This finding indicates the limitation of consumers' ability to understand functional evolution based on product form. Furthermore, Mugge and Dahl (2013) discovered that aesthetic newness had no impact on consumers' evaluation of the incremental functional evolution explained by text description.

In contrast to the previous frameworks regarding the relationships among product aesthetics, function, and advantage, we propose a new conceptual framework (see Figure 5). This framework aims at exploring the extent to which the evolution of function is perceived by consumers through product form and the function, perceived function and aesthetics have impacts on product advantages. The next chapter presents the empirical study based on this conceptual model.

Figure 5. Conceptual Framework

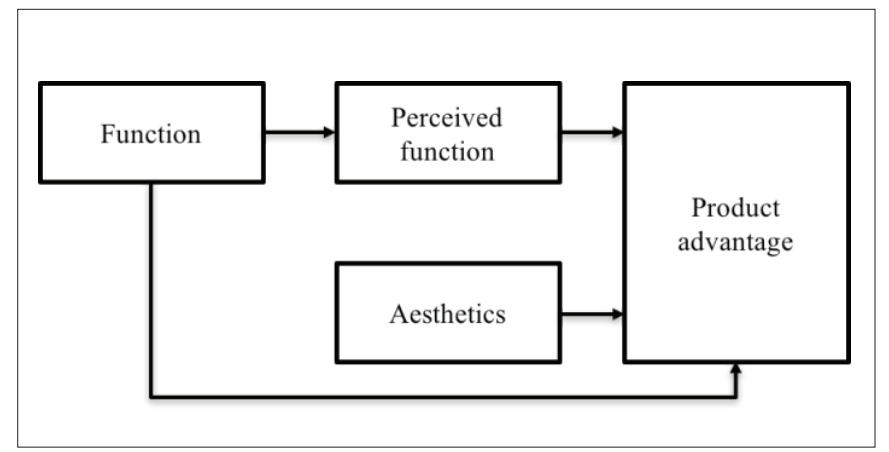




\section{Confirmatory and exploratory factor analysis}

This empirical test aims to evaluate the extent to which an evolution of the function is perceived by consumers through product form and then capture consumer perceptions of product advantages based on product form and function. The compact digital camera industry is chosen for this study as it provides a compelling setting in which to identify such values because of its high diffusion rate, modularised technology and a strong downward price pressure (Fehder, Nelling, and Trester, 2009).

\section{Data set}

This study employs a data set to represent users' evaluations of a product that were made based on their sensory perceptions; Kakaku.com is a web-based shopping service in Japan and was chosen as a data source. This website includes user ratings, which are direct feedback from users who have used the products, and descriptions of each item's technological specifications; it comparatively presents the prices offered by different sellers for the same product. On this website, users can post their five-level ratings to each presented review item for the specified digital camera. Each model has multiple user ratings as well as averaged ratings. Table 2 shows the items of the digital camera that the users review. The indexes include evaluations based on a relatively iconic functional feature for consumer and product form. The product was launched by four Japanese manufacturers (Panasonic, Canon, Sony, and Casio) from 2011 to 2014; it is used because Benner and Tripsas (2012) indicated that a firm's prior industry affiliation influenced technology choice. As all 112 products include multiple user ratings during this period, this study employs the averaged data of each product's multiple ratings.

Table 2. User Review Items

\begin{tabular}{|c|c|c|}
\hline & Item & Questions to Users \\
\hline Q1 & Aesthetics & How are the aesthetics? \\
\hline Q2 & Image quality & How is the image quality? \\
\hline Q3 & Mode of use & $\begin{array}{l}\text { Is the menu easy to operate? Is it easy to } \\
\text { set up? }\end{array}$ \\
\hline Q4 & Battery & Is the battery life long enough? \\
\hline Q5 & Portability & Is it compact? Is it easy to carry around? \\
\hline Q6 & $\begin{array}{l}\text { Image stabilisation } \\
\text { and camera modes }\end{array}$ & $\begin{array}{l}\text { How is the image stabilisation? } \\
\text { How are the camera modes? }\end{array}$ \\
\hline Q7 & Display & Is the screen easy to see? \\
\hline Q8 & Grip performance & Does it have a good grip? \\
\hline Q9 & Total & Total satisfaction \\
\hline
\end{tabular}

\section{Research design}

The initial exploratory analysis was conducted to identify perceived function and aesthetic impression in the data. The evaluative indexes include the following functions: image quality, battery life, compactness, camera modes, screen, and grip performance. There is theoretical identification of their few iconic functions; for example, image quality may be an iconic function that represents a digital camera. In a general way, the size of the image sensor, which the image quality depends on, affects the application of the lenses; thus, the form of the lens occupies an important role in product design. As a result, users may understand the evolution of the image quality through product form. Moreover, some studies have employed a panel of experts to identify the dimensions of perceived value in a product's appearance (Dell'Era and Verganti, 2011; Hertenstein et al., 2005; Veryzer, 2005). Users' functional evaluations through product form likely depend on their limited perception (Hoegg and Alba, 2011), which is driven by their individual experiences and expectations (Kreuzbauer and Malter, 2005). Thus, users' perceptions may be different when the function is identified theoretically or by a panel of experts. These methodologies are not suitable for this study because of its focus on the users' actual perception of objective function through product form. Thus, exploratory factor analysis is employed to identify perceived functionality and aesthetic impression in the data.

Next, confirmatory factor analysis is employed to examine the extent to which there is a relationship between the function and perceived function, which are identified by exploratory factor analysis; then, consumers assess the impacts of the function, perceived function, and aesthetic impression on product advantage.

\section{Identifying perceived function}

Exploratory factor analysis is used to identify perceived function and aesthetic impression in the data, which is described in Table 2 with the total satisfaction (Q9) removed. Table 3 displays the factor loadings and variance explained, and the eight items converge on two factors. The first six items-image stabilisation and camera modes (Q6), screen visibility (Q7), battery life (Q4), image quality (Q2), mode-of-use (Q3), and grip performance (Q8) - revealed strong loadings on Factor 1; aesthetics (Q1) and the portability of form (Q5) loaded on Factor 2. The theoretical discussion for each factor is provided as follows.

Table 3. Factor Loadings and Variance Explained

\begin{tabular}{lll}
\hline \multirow{2}{*}{ Item } & \multicolumn{2}{l}{ Factor Loading } \\
\cline { 2 - 3 } & Factor 1 & Factor 2 \\
\hline Q6 & 0.857 & -0.004 \\
Q7 & 0.838 & -0.066 \\
Q4 & 0.676 & -0.370 \\
Q2 & 0.660 & 0.325 \\
Q3 & 0.628 & -0.018 \\
Q8 & 0.534 & 0.116 \\
Q1 & 0.071 & 0.901 \\
Q5 & -0.019 & 0.488 \\
\hline Variance Explained $(\%)$ & 45.119 & 19.865 \\
\hline
\end{tabular}

Variance Explained (\%)

45.119

19.865

Extraction method: factor analysis; rotation method: varimax with Kaiser normalisation; total variance explained: $64.984 \% ; \mathrm{N}=112$.

As noted above, perceived product quality seems to be structured by utilitarian and hedonic values. A digital camera's predictive utilitarian values involve functions related to taking a picture. The items strongly loaded on Factor 1 provide an evaluation of these basic functions. These are the functions that users understand as being related to the actual use of the product. Therefore, Factor 1 is defined as utilitarian 
value. Meanwhile, Factor 2 is loaded by aesthetics (Q1) and portability (Q5), which relate to the artistic aspects that users perceive in a product's form. Thus, this factor is defined as hedonic value, meaning that Q5 is not a utilitarian value related to taking a picture for the users, although it is predicted that Q5 is physically influenced by technological specification (weight and thickness).

This result also indicates that image quality (Q2) and grip performance (Q8) loaded for both utilitarian and hedonic values, implying that the users perceive such functions through product forms. In general, these functions are the iconic features of the digital camera, which is illustrated in product form. This study therefore identifies these functions mediated by product form as perceived function, whereas visual attractiveness and beauty (Q1 and Q5) are identified as aesthetic impressions.

\section{Analysis of product advantages}

Exploratory factor analysis identifies the factors that users perceive from product forms. Then, confirmatory factor analysis is employed to examine the extent to which there is a relationship between function and perceived function, and consumers assess the impact of function, perceived function, and aesthetic impression on product advantage.

A partial least squares structural equation modelling (PLS-SEM) estimation approach is used to test this theoretical model (Hair, Sarstedt, Ringle, and Mena, 2012). Although the SEM approach also includes covariance-based SEM (CB-SEM), PLS-SEM is more suitable when the theory is less developed and when the goal involves identifying key driver constructs (Hair, Hult, Ringle, and Sarstedt, 2017). Table 4 illustrates the indicators, and Figure 6 describes the path model.

Table 4. Indicators

\begin{tabular}{ll}
\hline Product Advantage (PA) \\
\hline PA_1 & Taunching price \\
PA_2 & Pixel satisfaction \\
\hline Specification (SP) \\
\hline SP_1 & Sensor size \\
SP_2 & Thickness \\
SP_3 & Is it compact? Is it easy to carry around? (Q5) \\
SP_4 & How is the image quality? (Q2) \\
\hline Perceived function (PF) & Does it have a good grip? (Q8) \\
\hline PF_1 & How are the aesthetics? (Q1) \\
\hline PF_2 & Aesthetic Impression (AI) \\
\hline AI_1 &
\end{tabular}

Figure 6. Path Model

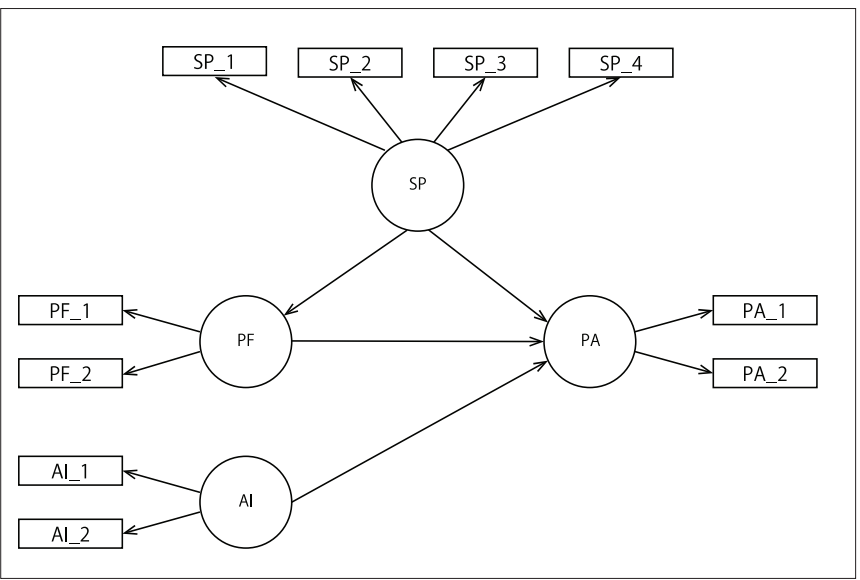

The perceived function (PF) and aesthetic impression (AI) are quoted from the previous factor analysis results. The specification (SP) has four measured indicator variables obtained from Kakaku.com: pixel and sensor size, on which PF_1 depends, and weight and thickness, on which PF_2 depends. The product advantage (PA) includes the launching prices obtained from Kakaku.com and the users' total satisfaction (Q9 in Table 2). Product price has a relationship with the characteristics that represent product quality; however, the downward price pressure of the digital camera is independent of technological evolution (Fehder et al., 2009). Therefore, Fehder et al. (2009) used hedonic models to illustrate the relationship between a digital camera's price and its changes in quality and referred to the price in a product's first week on the market to analyse technological shocks. Additionally, the total satisfaction obtained from Kakaku.com equals the comprehensive product value as perceived by the users.

The path model displays the relationships between PA and SP, PF and AI. SP has a durable path to predict PA; one is a direct effect, and the other is an indirect effect as mediated by PF. The indirect path is the mediating effect to explain how the users perceive the results of technological development from product forms.

The data obtained from Kakaku.com include the collection of questionnaires during the same period of time. Therefore, this paper conducted Harman's single-factor test to confirm the presence of common method effects (Podsakoff and Organ, 1986). The result indicates that the first factor did not account for a majority of the variance $(45.939 \%)$. Thus, the test failed to identify the common method variance as a problem.

\section{Result}

Table 5 illustrates the various constructs' outer loadings. The two indicators (SP_1 and AI_2) are eliminated in the exploratory analysis process because their outer loadings are less than 0.4 (Hair et al., 2017). The remaining indicators' outer loadings are all 0.7 or higher. Cronbach's $\alpha$ is the traditional criterion used to evaluate internal consistency, but it is not suitable for PLS-SEM because of a severe underestimation when using a small number of items in the scale 
(Wong, 2016). Composite reliability is employed instead of Cronbach's a to evaluate internal consistency reliability (Wong, 2016). The com- posite reliability results are acceptable because they are all greater than 0.7 and do not surpass 0.95 (Hair et al., 2017).

Table 5. Results of Outer Loadings' Significance Testing

\begin{tabular}{|c|c|c|c|c|c|}
\hline Latent Variables & Indicators & Outer Loadings & t-value & Composite Reliability & AVE \\
\hline \multirow[t]{2}{*}{$\mathrm{PA}$} & PA_1 & 0.841 & $22.204^{* * *}$ & 0.796 & 0.661 \\
\hline & PA_2 & 0.784 & $21.973^{* * *}$ & & \\
\hline AI & AI_1 & 1.000 & - & - & - \\
\hline \multirow[t]{2}{*}{ PF } & PF_1 & 0.927 & $48.974^{\star * *}$ & 0.840 & 0.725 \\
\hline & PF_2 & 0.769 & $10.242^{\star * *}$ & & \\
\hline \multirow[t]{2}{*}{ SP } & SP_2 & 0.824 & $12.265^{\star * *}$ & 0.935 & 0.827 \\
\hline & SP_4 & 0.945 & $75.654^{* * *}$ & & \\
\hline
\end{tabular}

All constructs in average variance extracted (AVE) satisfied the level that should be greater than 0.5 (Hair et al., 2017). Discriminant validity is tested using the Fornell-Larcker criterion (Fornell and Larcker, 1981), and the results provided in Table 6 demonstrate that the discriminant validity is adequate. We also evaluate the structural model in addition to testing the measurement model. The results of collinearity assessment and the effect size are provided in Appendix A. All variance inflation factor (VIF) values are less than 5 , and all $\mathrm{f}^{2}$ values are greater than 0.35 .

Table 6. Fornell-Larker criterion

\begin{tabular}{|c|c|c|c|c|c|}
\hline & \multicolumn{4}{|c|}{ Latent Variable Correlations (LVCs) } & \multirow[t]{2}{*}{ Discriminant Validity Met? } \\
\hline & PA & SP & AI & $\mathrm{PF}$ & \\
\hline PA & 0.813 & & & & Yes \\
\hline AI & 0.511 & 0.069 & - & & Yes \\
\hline PF & 0.729 & 0.377 & 0.557 & 0.852 & Yes \\
\hline
\end{tabular}

Figure 7 presents the relationships between each construct. This result demonstrates that all constructs supported a positive effect on PA ( $\mathrm{p}<0.001)$, and SP has the strongest impact. This paper's theoretical framework indicates that users perceive technological changes through a product's form, although the $\mathrm{R}^{2}$ value of PF is less than 0.25 , and thus SP cannot adequately explain the variance in PF. Therefore, the indirect effect between SP and PA through PF should be considered, and the mediating effect can be examined using Preacher and Hayes' (2008) procedure. Table 7 presents the results of the mediating effect, which indicate that no indirect effect on PA exists through PF.
Figure 7. PLS Path Model Estimation

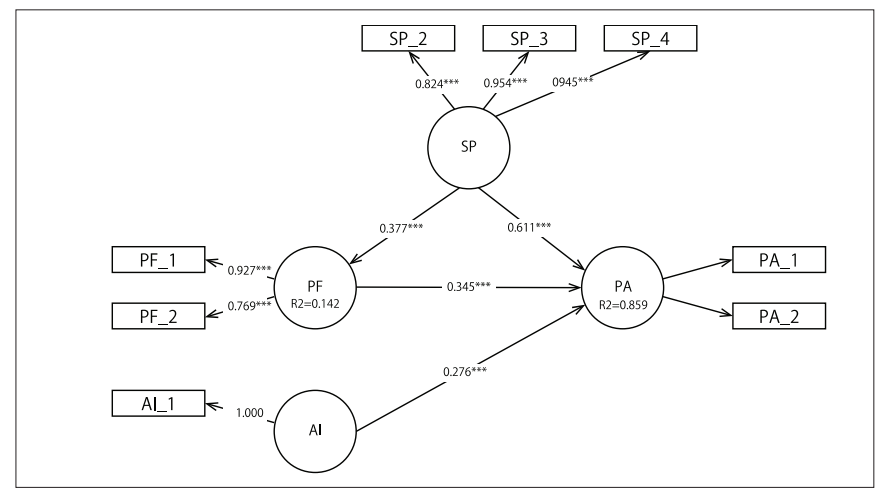

Table 7. Mediation Analysis

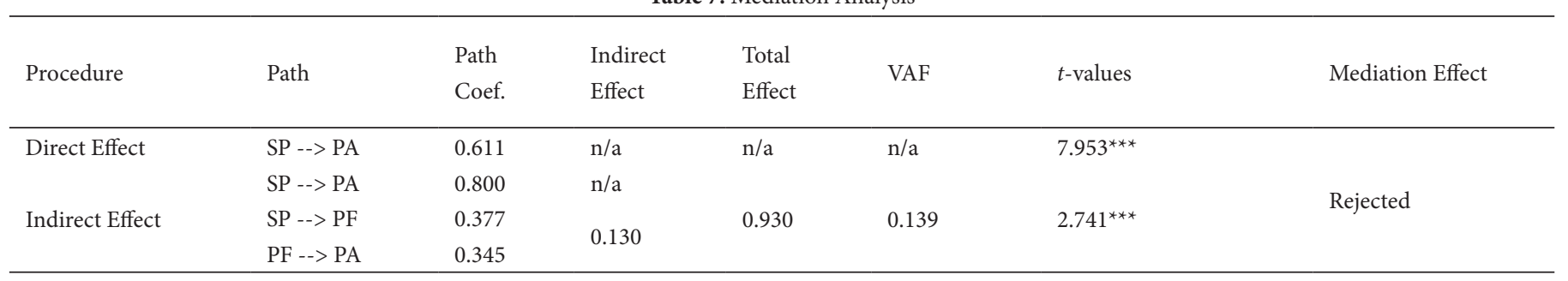




\section{Discussion}

Whilst the specification supported the positive effect on perceived functionality, the $\mathrm{R}^{2}$ value of $\mathrm{PF}$ was less than 0.25 . Thus, the specification cannot adequately explain the variance in perceived function. Moreover, there is no indirect effect of the specification on product advantage through perceived function. These findings imply that reflecting such incremental technological changes in product form would have a relatively small impact, and perceived function is more likely affected by other factors. Meanwhile, the function described by the specification demonstrated a stronger effect on product advantage than on perceived function through product form. The finding shows that the evolution of function is unlikely to be evaluated by perceived function.

According to Hoegg and Alba (2011), the users' functional evaluation through product form is limited to perceptions structured by individual product experiences (Kreuzbauer and Malter, 2005). For example, a new product imitating the form of another product that has an advanced function would make users perceive the new item as similarly superior to other products, even if it is actually inferior to the others. Hoegg and Alba (2011, p. 356) notes that 'it is likely that most visual differences in functional performance are not overwhelming and must be emphasised through marketing effort'. Therefore, despite the recent attention to aesthetic innovation, communication of functional advantage to consumers through marketing efforts is nonetheless important. This tendency is also supported by our observation of a stronger effect demonstrated by specification than aesthetic impression and perceived function on product advantage.

Moreover, our results highlight that the combination of higher perceived function and ergonomic advantage communicates product innovativeness (Moon et al., 2015) although Borneman et al. (2015) indicated that the impact of ergonomics on product advantage is independent from the level of function. In these studies, ergonomic advantage is the perception that consumers perceive and understand through product form as well as perceived function. Thus, in these studies, the evaluation of the ergonomic advantage perceived by visual sense is influenced by perceived function (Moon et al., 2015) but not by function (Borneman et al., 2015).

Although 'understanding experiential products such as automobiles is not merely a matter of evaluating a list of technical specifications' (Kreuzbauer and Malter, 2005, p. 169), understanding products through their forms is limited and distorted. The degree of betterment can be perceived through the product's parameters and the users' actual use as utilitarian value. This implies the necessity to focus on both technology and product form (Candi and Saemundsson, 2011; Creusen and Schoormans, 2005).

\section{Conclusion}

Theoretical studies have emphasised that products should reflect technology development in their forms, regardless of radical or incremental innovation. However, empirical studies have yet to explore the impact of technology through product form on product advantage. Integrating these theoretical and empirical perspectives, this study found that the consumer perception of technology in product form is judged in two domains of product value-utilitarian and hedonic-which consumers evaluate based on product specifications and actual use and based on observing its forms, respectively. This study defined the consumer perception of technology in a product that generates both the utilitarian and hedonic values as 'perceived function' and conducted a comprehensive analysis of the impact of functions, perceived function, and aesthetic impression on product advantage. First, this study contributes to the theoretical understanding of a product form's role in communicating its functional features. Most previous literature neglected the difference between function and perceived function (see Hoegg and Alba, 2011). This conceptual confusion seems to have been a barrier to progressively understanding the trade-offs between ergonomic value and function in product form. The present study found that the evolution of function has a relatively small impact on perceived function that serves as a product's iconic feature. Thus, the evaluation of the ergonomic advantage perceived by visual sense is influenced not by function but by perceived function.

Second, the study contributes to the discussion on the performance of design in innovation management. Previous empirical studies have separately discussed product form and function, but this study comprehensively examined product form and the description of technology development through which consumers perceived utilitarian and hedonic values. The findings reveal that consumers tend to evaluate technology development based on descriptions of technological specifications and the actual use of the product rather than based on observing product forms. Thus, technology development is worth further investigation, although there is an increased emphasis on the power of product form.

Additionally, our methodology contributes to developing a comprehensive analysis of function and product form. The existing literature primarily evaluated function as a utilitarian value only through consumers' visual perceptions of a product's appearance. Alternatively, this study's data source involves users' responses to actual use, which allowed us to identify utilitarian values that users also perceived from product form and then examine how changes in product form and description of technology development generate product advantages. Moreover, the data set involves two methodological advantages compared to the above studies' data sources-it is accessible to anyone, and it has abundant data (reviews). Fehder et al. (2009) demonstrated the usefulness of such a data set as a novel source for econometric analysis. This empirical analysis is beneficial for managers who struggle to understand the performance of technology and design.

\section{Limitations and future directions}

Despite the contributions here, we also note a limitation of this study. The exploratory factor analysis failed to categorise the mode of use as an ergonomic advantage, regardless of the indication from theoretical studies (Crilly et al., 2004). The data set has a weakness in that attributes of the survey respondents and their evaluation processes are out of our control, although it has the abovementioned merits. 
Product development is a highly aesthetic and technological activity in which countless, mutually influential factors are involved. Despite the limitation, our introduction of the concept of 'perceived function' may shed light on a new aspect of research on technology and design. We hope this study will be a starting point for the emergence of a new stream of research on human-product interactions.

\section{Biographical notes}

Satoru Goto is currently an associate professor at Ritsumeikan University, Japan. He received his $\mathrm{PhD}$ in the Technology Management from Ritsumeikan University. He has an undergraduate degree and a master's degree in Science and Engineering from Ritsumeikan University. His current research interests are product-service systems and innovation of meaning. His articles have been published in the Journal of Technology Management and Innovation.

Yuuki Shigemoto is Lecturer in Marketing at Toyama University of International Studies in Japan. He was a doctoral researcher at the University of Cambridge when this paper was written, and has been a fellow of the Design Management Lab at Ritsumeikan Unviersity, a Senior Project Researcher at Keio University, and a Co-founder, Director and Design Manager at House of Craftsmen. Co., Ltd. His main research interests concern socio-cultural factors that affect consumer perception for designer intent which is shaped as products.

Shuichi Ishida is Professor of Technology and Engineering management at Ritsumeikan University. His research focuses on technology strategy and R\&D organization, high-tech entrepreneurship, management systems. In particular, his current research concern is based on perspectives of factors influencing Japanese auto suppliers' predictions about the future of innovative technologies such as electric vehicles.

\section{References}

Benner, M. J., \& Tripsas, M. (2012). The influence of prior industry affiliation on framing in nascent industries: the evolution of digital cameras. Strategic Management Journal, 33(3), 277-302. doi: 10.1002/smj.950

Bloch, P. H. (1995). Seeking the ideal form: product design and consumer response. Journal of Marketing, 59(3), 16-29. doi: $10.2307 / 1252116$

Bornemann, T., Schöler, L., \& Homburg, C. (2015). In the eye of the beholder? The effect of product appearance on shareholder value. Journal of Product Innovation Management, 32(5), 704-715. doi: 10.1111/jpim. 12228

Boztepe, S. (2007). User value: competing theories and models. International Journal of Design, 1(2), 55-63.

Buganza, T., Dell'Era, C., Pellizzoni, E., Trabucchi, D., \& Verganti, R. (2015). Unveiling the potentialities provided by new technologies: A process to pursue technology epiphanies in the smartphone app industry. Creativity and Innovation Management, 24(3), 391-414. doi: $10.1111 /$ caim. 12141
Candi, M. (2006). Design as an element of innovation: evaluating design emphasis in technology-based firms. International Journal of Innovation Management, 10(4), 351-374. doi: 10.1142/ S1363919606001533

Candi, M., \& Saemundsson, R. J. (2011). Exploring the relationship between aesthetic design as an element of new service development and performance. Journal of Product Innovation Management 28(4): 536-557. doi: 10.1111/j.1540-5885.2011.00827.x

Chang, T. -Z., \& Wildt, A. R. (1994). Price, product information, and purchase intention: an empirical study. Journal of the Academy of Marketing Science, 22(1), 16-27. doi: 10.1177/00920703942

Chitturi, R., Raghunathan, R., \& Mahajan, V. (2008). Delight by design: the role of hedonic versus utilitarian benefits. Journal of Marketing, 72(3), 48-63. doi: 10.1509/jmkg.72.3.48

Creusen, M. E. H. (2011). Research opportunities related to consumer response to product design. Journal of Product Innovation Management, 28(3), 405-408. doi: 10.1111/j.1540-5885.2011.00812.x

Creusen, M. E. H., \& Schoormans, J. P. L. (2005). The different roles of product appearance in consumer choice. Journal of Product Innovation Management, 22(1), 63-81. doi: 10.1111/j.07376782.2005.00103.x

Crilly, N., Maier, A., \& Clarkson, P. J. (2008). Representing artefacts as media: modelling the relationship between designer intent and consumer experience. International Journal of Design, 2(3), 15-27.

Crilly, N., Good, D., Matravers, D., \& Clarkson, P. J. (2008). Design as communication: exploring the validity and utility of relating intention to interpretation. Design Studies, 29(5), 425-457. doi: 10.1016/j. destud.2008.05.002

Crilly, N., Moultrie, J., \& Clarkson, P. J. (2004). Seeing things: consumer response to the visual domain in product design. Design Studies, 25(6), 547-577. doi: 10.1016/j.destud.2004.03.001

Dell'Era, C., \& Verganti, R. (2011). Diffusion processes of product meanings in design-intensive industries: determinants and dynamics. Journal of Product Innovation Management, 28(6), 881-895. doi: 10.1111/j.1540-5885.2011.00849.x

Eisenman, M. (2013). Understanding aesthetic innovation in the context of technological evolution. Academy of Management Review, 38(3), 332-351. doi: 10.5465/amr.2011.0262

Elliott, R. (1997). Existential consumption and irrational desire. European Journal of Marketing, 31(3), 285-296. doi: 10.1108/03090569710162371

Fehder, D. C., Nelling, E., \& Trester, J. J. (2009). Innovation and price: the case of digital cameras. Applied Economics, 41(17), 2229-2236. doi: 10/1080/00036840701222488 
Fornell, C., \& Larcker, D. F. (1981). Evaluating structural equation models with unobservable variables and measurement error. Journal of Marketing Research, 18(1), 39-50. doi: 10.2307/3151312

Gemser, G., \& Leenders, M. A. A. M. (2001). How integrating industrial design in the product development process impacts on company performance. Journal of Product Innovation Management, 18(1), 2838. doi: 10.1111/1540-5885.1810028

Hair, J. F., Hult, G. T. M., Ringle, C. M., \& Sarstedt, M. (2017). A primer of partial least squares structural equation modeling (PLS-SEM) (2nd ed.). Thousand Oaks, CA: Sage. doi:10.1080/1743727X.2015.1005806

Hair, J. F., Sarstedt, M., Ringle, C. M., \& Mena, J. A. (2012). An assessment of the use of partial least squares structural equation modeling in marketing research. Journal of the Academy of Marketing Science, 40(3), 414-433. doi: 10.1007/s11747-011-0261-6

Hanzaee, K. H., \& Baghi, M. (2011). Evaluating the dimensions of the role of product design (hedonic and utilitarian) in consumer's postconsumption emotions and purchase intention. Middle-East Journal of Scientific Research, 8(3), 637-647.

Hertenstein, J. H., Platt, M. B., \& Veryzer, R. W. (2005). The impact of industrial design effectiveness on corporate financial performance. Journal of Product Innovation Management, 22(1), 3-21. doi: 10.1111/j.0737-6872.2005.00100.x

Hirschman, E. C., \& Holbrook, M. B. (1982). Hedonic consumption: emerging concepts, methods and propositions. Journal of Marketing, 46, 92-101. doi: 10.2307/1251707

Hoegg, J., \& Alba, J. W. (2011). Seeing is Believing (too much): the influence of product form on perceptions of functional performance. Journal of Product Innovation Management, 28(3), 346-359. doi: 10.1111/j.1540-5885.2011.00802.x

Kaplan, S., \& Tripsas, M. (2008). Thinking about technology: applying a cognitive lens to technical change. Research Policy, 37(5), 790-805. doi: 10.1016/j.respol.2008.02.002

Kenrick, D. T., Griskevicius, V., Sundie, J. M., Li, N. P., Li, Y. J., \& Neuberg, S. L. (2009). Deep rationality: the evolutionary economics of decision Making. Social Cognition, 27(5), 764-785. doi: 10.1521/ soco.2009.27.5.764

Kreuzbauer, R., \& Malter, A. J. (2005). Embodied cognition and new product design: changing product form to influence brand categorization. Journal of Product Innovation Management, 22(2), 165-176. doi: 10.1111/j.0737-6782.2005.00112.x

Lichtenstein, D. R., \& Burton, S. (1989). The relationship between perceived and objective price-quality. Journal of Marketing Research, 26(4), 429-443. doi: 10.2307/3172763
Moon, H., Park, J., \& Kim, S. (2015). The importance of an innovative product design on customer behavior: development and validation of a scale. Journal of Product Innovation Management, 32(2), 224-232. doi: 10.1111/jpim.12172

Mugge, R., \& Dahl, D. W. (2013). Seeking the ideal level of design newness: consumer response to radical and incremental product design. Journal of Product Innovation Management, 30(S1), 34-47. doi: 10.1111/jpim.12062

Norman, D. A. (2004). Emotional design: why we love (or hate) everyday things. New York: Basic Books.

Oude Ophuis, P. A. M., \& Van Trijp, H. C. M. (1995). Perceived quality: A market driven and consumer oriented approach. Food Quality and Preference, 6(3), 177-183. doi: 10.1016/0950-3293(94)00028-T

Podsakoff, P. M., \& Organ, D. W. (1986). Self-reports in organizational research: problems and prospects. Journal of Management, 12(4), 531-544. doi: 10.1177/014920638601200408

Preacher, K. J., \& Hayes, A. F. (2008). Asymptotic and resampling strategies for assessing and comparing indirect effects in multiple mediator models. Behavior Research Methods, 40(3), 879-891. doi: 10.3758/BRM.40.3.879

Rampino, L. (2011). The innovation pyramid: A categorization of the innovation phenomenon in the product-design field. International Journal of Design, 5(1), 3-16.

Ravasi, D., \& Stigliani, I. (2012). Product design: a review and research agenda for management studies. International Journal of Management Reviews, 14(4), 464-488. doi: 10.1111/j.1468-2370.2021.00330.x

Rubera, G., \& Droge, C. (2013). Technology versus design innovation's effects on sales and Tobin's Q: the moderating role of branding strategy. Journal of Product Innovation Management, 30(3), 448-464. doi: 10.1111/jpim.12012

Sheth, J. N., Newman, B. I., \& B. L. Gross. (1991). Why we buy what we buy: A theory of consumption values. Journal of Business Research, 22(2), 159-170. doi: 10.1016/0148-2963(91)90050-8

Shetty, Y. K. (1987). Product quality and competitive strategy. Business Horizons, 30(3), 46-52. doi: 10.1016/0007-6813(87)90036-X

Steenkamp, J. E. M. (1990). Conceptual model of the quality perception process. Journal of Business Research, 21(4), 309-333. doi: 10.1016/0148-2963(90)90019-A

Sweeney, J. C., \& Soutar, G. N. (2001). Consumer perceived value: the development of a multiple item scale. Journal of Retailing, 77(2), 203-220. doi: 10.1016/S0022-4359(01)00041-0 
Talke, K., Salomo, S., Wieringa, J. E., \& Lutz, A. (2009). What about design newness? Investigating the relevance of a neglected dimension of product innovativeness. Journal of Product Innovation Management, 26(6), 601-615. doi: 10.1111/j.15405885.2009.00686.x

Thompson, D. V., Hamilton, R. W., \& Rust, R. T. (2005). Feature fatigue: when product capabilities become too much of a good thing. Journal of Marketing Research, 42(4), 431-442. doi: 10.1509/ jmkr.2005.42.4.431

Toivonen, R. M. (2012). Product quality and value from consumer perspective-an application to wooden products. Journal of Forest Economics, 18(2), 157-173. doi: j.jfe.2011.12.004

Turel, O., Serenko, A., \& Bontis, N. (2010). User acceptance of hedonic digital artifacts: A theory of consumption values perspective. Information and Management, 47(1), 53-59. doi: 10.1016/j. im.2009.10.002
Veryzer, R. W. (2005). The roles of marketing and industrial design in discontinuous new product development. Journal of Product Innovation Management, 22(1), 22-41. doi: 10.1111/j.07376872.2005.00101.x

Voss, K. E., Spangenberg, E. R., \& Grohmann, B. (2003). Measuring the hedonic and utilitarian dimensions of consumer attitude. Journal of Marketing Research, 40(3), 310-320. doi: 10.1509/ jmkr.40.3.310.19238

Walsh, V., Roy, R., Bruce, M., \& Potter, S. (1992). Winning by design: technology, product design and international competitiveness. Cambridge, MA: Blackwell Publishing Business. doi: 10.1111/j.14679310.1994.tb00861.x

Wong, K. K. (2016). Mediation analysis, categorical moderation analysis, and higher-order constructs modeling in partial least squares structural equation modeling (PLS-SEM): A B2B example using SmartPLS. Marketing Bulletin, 26, 1-22. doi: 10.13140/ RG.2.1.1643.0562 


\section{Appendix}

Table A1. Collinearity Assessment

\begin{tabular}{ccc}
\hline & VIF & Collinearity Problem \\
\hline SP & 1.206 & No \\
AI & 1.501 & No \\
PF & 1.741 & No \\
\hline
\end{tabular}

Table A2. Results of $\mathrm{f}^{2}$ Effect Sizes

\begin{tabular}{lll}
\hline & $\mathrm{f}^{2}$ & \\
\hline & $\mathrm{PA}$ & $\mathrm{PF}$ \\
\hline $\mathrm{SP}$ & 2.184 & 0.165 \\
$\mathrm{AI}$ & 0.358 & $\mathrm{n} / \mathrm{a}$ \\
$\mathrm{PF}$ & 0.482 & $\mathrm{n} / \mathrm{a}$ \\
\hline
\end{tabular}

